\title{
DOI 10.1590/1807-01912014202273 Engajamento cívico e capital social: um modelo interativo para o efeito da confiança interpessoal
}

\begin{tabular}{c}
\hline \hline Alessandro Freire \\
Mestre em Ciência Política - Universidade de Brasília \\
Escola Nacional de Administração Pública \\
\hline \hline
\end{tabular}

Resumo: A teoria do capital social enfatiza a confiança interpessoal como um facilitador da cooperação entre os indivíduos, crucial para a formação de organizações autônomas da sociedade civil e para o engajamento dos cidadãos em questões de interesse público. Em que pese a centralidade da confiança para o conceito de capital social, pesquisas empíricas recentes têm demonstrado que o seu efeito sobre a participação cívica é, na melhor das hipóteses, fraco. Este artigo propõe um modelo empírico interativo, onde o efeito da confiança interpessoal é condicionado por elementos motivacionais da participação (expectativas de benefícios e percepções de custos). Usando dados do British Election Study (BES) de 2005, um survey conduzido no Reino Unido, testo o efeito condicional da confiança sobre a disposição dos indivíduos a se engajarem em diferentes tipos de ações coletivas. Os resultados apontam que o efeito condicional da confiança varia não apenas de acordo com variáveis motivacionais, mas, também, com o tipo de engajamento em questão.

Palavras-chave: confiança; engajamento; participação; custos; benefícios

\begin{abstract}
Social capital theory emphasizes interpersonal trust as a facilitator of cooperation among individuals, crucial for the formation of autonomous associations within civil society and for the engagement of citizens in public affairs. Despite the importance of trust for the concept of social capital, recent empirical research has been demonstrating that its effect on civic participation is weak, at best. This paper suggests an interactive model, where the effect of trust is conditioned by motivational aspects of participation (expectations of benefits and perceptions of costs). Using data from the 2005 British Election Study (BES), a survey conducted in the United Kingdom, I test the conditional effect of interpersonal trust on individuals' willingness to engage in different types of collective action. The findings point to a conditional effect of trust that varies not only according to motivation variables, but also depending on the type of engagement.
\end{abstract}

Keywords: trust; engagement; participation; costs; benefits 


\section{OPINIÃO PÚBLICA, Campinas, vol. 20, no 2, agosto, 2014, p. 273-290}

\section{Introdução ${ }^{1}$}

Uma das principais preocupações da Ciência Política contemporânea refere-se às causas da participação cívica, isto é, quais variáveis estão envolvidas na manutenção de uma sociedade politicamente ativa e atenta a assuntos de interesse público. A capacidade de associação autônoma dos cidadãos em torno de objetivos comuns é, frequentemente, um dos focos de interesse no estudo das instituições participativas.

Desde a publicação de "Political Man: The Social Bases of Politics" (LIPSET, 1960), e "The Civic Culture" (ALMOND e VERBA, 1963), as características do meio social passaram a figurar no meio acadêmico como importantes fatores para o sucesso da democracia, especialmente em países recém. saídos de experiências políticas autoritárias. A partir dessas obras, a confiança entre as pessoas ganhou destaque como uma variável essencial para a manutenção do livre associativismo e para o resguardo da democracia de maneira mais ampla.

A difusão de comportamentos e valores oportunistas seria, de acordo com abordagens "culturalistas" da democracia, desfavorável ao amadurecimento de instituições participativas. A incapacidade dos cidadãos de confiar em seus pares representaria um empecilho à formação de associações autônomas capazes de defender seus interesses na esfera pública. Em outras palavras, contextos sociais onde as expectativas das pessoas sobre a conduta alheia são muito negativas podem desfavorecer a mobilização política da sociedade civil.

No meio acadêmico, o vínculo entre a confiança interpessoal e o engajamento cívico tornou-se mais proeminente nas décadas de 1980 e 1990, período de transição para a democracia em diversos países da América Latina e do Leste Europeu. Vários autores aferiram à confiança interpessoal o status de variável central da cultura política democrática (INGLEHART, 1988; PUTNAM, 2006 [1993]; FUKUYAMA, 2001).

A constatação da falta de confiança como uma das principais causas duradouras da imobilização política parecia comprometer o funcionamento da democracia em países com baixos níveis de confiança interpessoal. A consequência desse diagnóstico era clara: sem um ambiente social favorável às instituições democráticas participativas, pouco se poderia esperar do seu desenvolvimento.

Apesar da ênfase de algumas teorias sobre os determinantes culturais da democracia, pesquisas empíricas recentes têm encontrado resultados pouco alentadores a respeito da importância da confiança para o estímulo à participação política. Diversos autores identificaram outras variáveis como mais relevantes do que a confiança para o engajamento da sociedade civil, tais como a disponibilidade de recursos para arcar com os custos da participação (BRADY et al, 1995), a intensidade motivacional (FIORINA, 2001), as estruturas de oportunidade oferecidas pelas instituições públicas (RENNó, 2003), entre outras. De fato, tendo em vista a centralidade que a confiança chegou a assumir nos estudos sobre cultura política, é intrigante que seu desempenho empírico venha sendo decepcionante (SELIGSON e RENNÓ, 2000)

A pouca atenção dada às motivações individuais para a participação política é um dos principais pontos de críticas às teorias culturalistas da democracia (JACKMAN \& MILLER, 1998; JOHNSON,

\footnotetext{
${ }^{1}$ Este artigo é baseado em minha dissertação de mestrado, concluída em 2012. Agradeço as contribuições e ótimos comentários de Lucio Rennó e Yan Carreirão, que compuseram minha banca, e dos pareceristas. Um agradecimento especial a Mathieu Turgeon, meu orientador, que teve papel central na pesquisa por sempre exigir um pouco mais das minhas capacidades e por suas excelentes críticas teóricas e metodológicas. Quaisquer erros deste artigo são de minha inteira responsabilidade.
} 
FREIRE, A. Engajamento cívico e capital social: um modelo interativo para o efeito...

2003). Um dos problemas do foco sobre a confiança interpessoal para o engajamento cívico está na presunção da existência latente de motivações, desconsiderando importantes aspectos de interesses individuais. Isto é, a associação direta entre confiança e cooperação política pode ser enganosa (LEVI, 1996).

De fato, é duvidosa a relação direta entre a confiança interpessoal e o engajamento cívico, dado que a decisão de participar envolve outras variáveis que podem condicionar seu efeito. Algumas dessas variáveis correspondem às expectativas de benefícios e aos custos da participação política, as quais foram objeto de estudo de autores vinculados à teoria da escolha racional (DowNS, 1957; RIKER e ORDESHOOK, 1968; ALDRICH, 1993). Embora muitos desses estudos voltassem suas atenções à participação eleitoral, esses aspectos instrumentais também foram considerados para formas menos convencionais de participação cívica (BRADY et al, 1995; PATTIE et al, 2003; VerBA et al, 2000).

É inegável que a participação em questões de interesse público acarreta custos individuais, os quais podem assumir diferentes formas (disponibilidade de tempo, recursos financeiros, capacidades cognitivas, entre outros). Como demonstraram Brady et al (1995), o tempo livre e a capacidade de arcar com custos financeiros são importantes variáveis para o engajamento cívico (BRADY et al, 1995 p.284). Analogamente, as expectativas de benefícios parecem afetar positivamente a disposição dos cidadãos para envolverem-se em atividades de natureza política (PATTIE et al, 2003).

Apesar da importância das variáveis supracitadas, grande parte dos estudos sobre o capital social carece de uma análise aprofundada sobre como a confiança interpessoal interage com aspectos instrumentais do engajamento cívico. Diante dessa carência, torna-se necessário detalhar o mecanismo que vincula a confiança interpessoal à motivação para o engajamento dos cidadãos em ações coletivas. Esse é o principal objetivo deste artigo.

\section{Teoria}

De acordo com a teoria do capital social, a confiança atua como um incentivo positivo para o engajamento cívico, reduzindo as incertezas quanto ao comportamento de outros atores envolvidos em ações coletivas. Dado que grande parte dos problemas de interesse das Ciências Sociais envolve a coordenação de expectativas dos atores diante de incertezas (RUNGE, 1984, p. 175.176), a confiança interpessoal pode, de fato, figurar como importante elemento para a participação política.

A estratégia dominante de não cooperação em ações coletivas para o provimento de bens públicos, predita por Olson (1965), é refutada por diversos exemplos cotidianos. As pessoas constantemente formam grupos com o objetivo de prover bens coletivos voluntariamente, tal como ocorre nos partidos políticos, nas associações filantrópicas, nos sindicatos e em diversas outras instâncias. Entretanto, como destacou Ostrom (2000), ainda que as expectativas teóricas de Olson (1965) tenham sido refutadas por estudos empíricos, esses achados ainda não foram integrados em uma teoria revisada da ação coletiva.

Um dos achados que pode explicar a falha da teoria proposta por Olson (1965) é destacado por Ostrom: "Those who believe others will cooperate in social dilemmas are more likely to cooperate themselves. A rational egoist, however, should not in any way be affected by a belief regarding the contribution levels of others" (OSTROM, 2000, p.140).

Se a expectativa quanto à conduta alheia desempenha importante papel na decisão de contribuir para ações coletivas, é possível que a confiança interpessoal, variável-chave do conceito de 
capital social, atue como um facilitador da cooperação. Nesse sentido, duas correntes teóricas aparentemente contrastantes, as teorias do capital social e da escolha racional, podem, na verdade, ser complementares.

O papel da confiança nos dilemas da ação coletiva não é, evidentemente, uma preocupação exclusiva dos teóricos do capital social, sendo enfatizado por diversos teóricos da escolha racional (ELSTER, 1979; OSTROM, 2000; RUNGE, 1984). De acordo com Runge (1984), os dilemas da ação coletiva estão associados a um problema de garantia (assurance problem). No problema da garantia, as escolhas interdependentes dos atores criam incentivos para o estabelecimento e a manutenção de instituições que coordenam expectativas baseadas em regras de justeza (RUNGE, 1984, p.154). Diante de expectativas devidamente coordenadas, contribuições voluntárias para o provimento de bens públicos poderiam constituir estratégias de maximização de utilidade (RUNGE, idem).

Essa asserção é compatível com alguns dos pressupostos da teoria do capital social, uma vez que a confiança interpessoal é tida como uma instituição informal capaz de reduzir a incerteza característica do engajamento cívico. O problema da incerteza é característico das interações entre atores na teoria dos jogos. No "dilema do prisioneiro", a estratégia ótima para ambos os atores envolvidos é a deserção. A cooperação seria a estratégia de maior risco para ambos, em virtude da possibilidade de deserção, levando a um resultado individualmente ótimo, porém, coletivamente sub. ótimo. Essa estratégia seria, de acordo com a teoria dos jogos, independente das expectativas quanto às ações de outros atores.

Entretanto, Runge (1984) e outros autores (ELSTER, 1979; NURMI, 1977; BAUMOL, 1976) contestam essa ideia, afirmando a importância das expectativas sobre as estratégias de outros jogadores:

\footnotetext{
"Wherever benefits and costs are a function of the total actions of the group, it seems implausible that decisions to contribute are unaffected by expectations of the decisions of others (see ELSTER, 1979; NURMI, 1977). Formally, in all nonseparable cases, optimal choices are defined in terms not only of one's own choice variable but also the choices of others (BAUMOUL, 1976)" (RUNGE, 1984, p.160).
}

Se as expectativas quanto à conduta de outrem podem ser consideradas importantes para a decisão individual sobre cooperar ou desertar em dadas situações, as instituições desempenham papel crucial no fomento à cooperação, conclui Runge (1984).

Embora essa seja uma das premissas da teoria do capital social, a desconsideração das motivações individuais para o engajamento cívico por parte de muitos de seus defensores conferiu à confiança interpessoal uma centralidade duvidosa na análise do engajamento cívico. Isto é, em geral, esses autores parecem entender a predisposição para o engajamento como uma regra do comportamento dos atores, sendo a falta de confiança entre as pessoas o principal empecilho, mas há evidências que indicam o contrário (FIORINA, 1999; 2001).

Se o efeito da confiança for tomado como condicional para a participação em ações coletivas, aproximando-o à concepção de capital social originalmente proposta por Coleman (1988), é possível que seu papel se torne mais nítido. Nesse sentido, a confiança interpessoal, quando aliada a motivações individuais, poderia reforçar a disposição de um indivíduo engajar-se em ações coletivas de natureza 
FREIRE, A. Engajamento cívico e capital social: um modelo interativo para o efeito...

política. Analogamente, é possível imaginar que a falta de confiança possa minar a disposição para a participação cívica.

A confiança interpessoal não parece ter o efeito de impulsionar o engajamento, mas de estimular aqueles que dispõem de tal impulso a contribuírem ativamente para o provimento de bens coletivos. Isso quer dizer que, ceteris paribus, a confiança interpessoal pode aumentar as chances de uma pessoa se engajar no provimento de bens coletivos quando aliada à percepção dos custos e expectativas dos benefícios individuais e coletivos do engajamento.

\section{Hipótese: $O$ efeito condicional da confiança interpessoal}

A hipótese aqui levantada é que a confiança interpessoal tem um efeito condicional positivo sobre o engajamento dependendo das motivações individuais para tal. Isto é, a confiança interpessoal só deve surtir efeitos positivos sobre o engajamento diante de percepções de custos relativamente baixas e expectativas de benefícios relativamente altas. Pessoas mais motivadas a participar podem ser mais afetadas pela confiança do que aquelas menos motivadas. Em contraste, aqueles menos motivados a se engajarem devem ser consideravelmente menos afetados pela confiança interpessoal. Como propõe Ostrom: "Conditional cooperators are individuals who are willing to initiate cooperative action when they estimate others will reciprocate and to repeat these actions as long as a sufficient proportion of others reciprocate" (OSTROM, 2000, p.142). Fica evidente, portanto, que as normas de reciprocidade previstas pela teoria do capital social também estão inseridas nas abordagens da escolha racional sobre os dilemas da ação coletiva. Nesse sentido, a hipótese a ser testada pode ser assim descrita:

H1 - A confiança interpessoal tem um efeito condicional positivo sobre o engajamento cívico quando aliada a expectativas altas de benefícios e percepções baixas de custos da participação.

Dessa forma, a partir de uma hipótese condicional, testo o efeito interativo da confiança sobre a disposição para o engajamento em três tipos de atividades: I - participação em partidos políticos; II participação em protestos; III - participação em associações voluntárias. Todas essas atividades diferem consideravelmente da participação eleitoral por exigirem fortes compromissos dos participantes (RENNÓ, 2001).

Vale notar que a hipótese aqui levantada enfatiza a confiança interpessoal como uma variável independente para o engajamento cívico, muito embora a teoria do capital social estabeleça uma relação de via dupla entre essas variáveis (PUTNAM, 2006 [1993]). De fato, alguns achados sugerem que a relação causal entre a confiança interpessoal e a participação cívica ocorre somente quando a primeira é tomada como um produto da segunda (BREHM \& RAHM, 1997; CLAIBOURNE \& MARTIN, 2000). Dessa forma, ao testar-se o efeito da confiança interpessoal sobre o engajamento cívico, é possível avaliar se essas variáveis compõem de fato um "ciclo virtuoso", como apontado por Putnam (2006 [1993]).

A seguir, apresento a metodologia adotada. O modelo interativo apresentado segue as orientações da literatura mais recente sobre hipóteses condicionais (BRAMBOR et al, 2005; KAM e FRANZESE, 2005; BRAUMOELLER, 2004). 


\section{Metodologia}

Com o objetivo de testar o efeito condicional da confiança interpessoal sobre o engajamento cívico, foram recolhidos dados de um survey, o British Election Study (BES) de 2005. A escolha pelo banco de dados do BES 2005 foi baseada, principalmente, na alta representatividade da amostra e na correspondência das perguntas contidas no questionário do survey inglês com os temas de interesse teórico desta pesquisa. Por fim, coletar dados sobre o engajamento cívico britânico pode ser uma boa forma de analisar as premissas teóricas do capital social, uma vez que o Reino Unido é tido como um paradigma da relação entre confiança interpessoal e a propensão para a participação cívica (ALMOND e VERBA, 1989 [1963]).

O questionário do BES 2005 contém diversas perguntas que serviram de base para a definição das variáveis dependentes e independentes desta pesquisa. As perguntas que constituem as variáveis dependentes são compostas por escalas que mensuram o quanto os entrevistados se sentem dispostos a se engajarem em determinadas atividades.

Para mensurar a propensão dos indivíduos para o engajamento cívico foram utilizadas perguntas com escalas que variam de 0 (muito pouco provável) a 10 (muito provável). Os tipos de atividades contemplados são os seguintes:

Participação em campanhas de partidos políticos - Dentre as variáveis dependentes selecionadas relativas à propensão para o engajamento, a participação em campanhas político-partidárias foi a que apresentou a menor média. Os entrevistados se mostraram muito pouco dispostos a trabalharem para um partido político.

Participação em protestos - Assim como na propensão para o engajamento em partidos políticos, os entrevistados declararam-se muito pouco inclinados a se envolverem em protestos, embora relativamente mais dispostos a participar de tal tipo de ação coletiva.

Participação em associações voluntárias - Os entrevistados revelaram-se mais propensos ao associativismo, em comparação à participação em campanhas partidárias ou em protestos. Ainda assim, a propensão média da amostra indicou que a inclinação ao desengajamento em associações voluntárias aparece como dominante. 
FREIRE, A. Engajamento cívico e capital social: um modelo interativo para o efeito...

Tabela 1

Variáveis Dependentes

\begin{tabular}{|c|c|c|c|c|c|}
\hline Variável & Média & $\begin{array}{c}\text { Desvio- } \\
\text { padrão }\end{array}$ & Mínimo & Máximo & N \\
\hline Trabalhar para uma campanha partidária & 1,21 & 2,11 & 0 & 10 & 3554 \\
\hline Participar de protestos & 2,57 & 2,88 & 0 & 10 & 3548 \\
\hline Participar de uma associação voluntária & 4,54 & 3,53 & 0 & 10 & 3549 \\
\hline
\end{tabular}

Fonte: Elaboração própria a partir do British Election Study 2005.

A seguir, apresento a relação de variáveis independentes de interesse do modelo. Algumas dessas variáveis foram compostas por índices originados a partir da média de duas ou mais perguntas retiradas do questionário. A escolha pela construção de índices é justificada pela cautela quanto ao problema dos erros de mensuração que permeiam os surveys, especialmente no tocante às atitudes políticas dos entrevistados. Dessa forma, este artigo seguiu as orientações de Ansolabehere et al (2008) para a elaboração de indicadores de atitudes.

Tabela 2

Variáveis Independentes

\begin{tabular}{|l|c|c|c|c|c|}
\hline \multicolumn{1}{|c|}{ Variável } & Média & $\begin{array}{c}\text { Desvio } \\
\text { Padrão }\end{array}$ & Mínimo & Máximo & N \\
\hline Confiança interpessoal & 6,29 & 1,83 & 0 & 10 & 3539 \\
\hline Custos da participação & 3,12 & 0,93 & 1 & 5 & 3531 \\
\hline Benefícios da participação & 2,72 & 0,71 & 1 & 5 & 3485 \\
\hline Renda & 5,46 & 3,34 & 1 & 13 & 4036 \\
\hline Idade & 50,48 & 16,95 & 18 & 97 & 3548 \\
\hline Confiança nas instituições & 5,12 & 2,12 & 0 & 10 & 3490 \\
\hline Eficácia externa & 3,38 & 0,93 & 1 & 5 & 3299 \\
\hline Eficácia interna & 2,63 & 2,28 & 0 & 10 & 3543 \\
\hline Interesse político & 0,51 & 0,08 & 0.12 & 0.90 & 3552 \\
\hline Educação & 2,56 & 1,53 & 1 & 5 & 4036 \\
\hline Conhecimento político & 5,43 & 1,75 & 0 & & 8 \\
\hline Sexo & 0,45 & 0,49 & 0 & & 1 \\
\hline
\end{tabular}

Fonte: Elaboração própria a partir do British Election Study 2005.

Confiança interpessoal - Mensurada a partir de duas perguntas, assumindo um intervalo de 0 (nenhuma confiança) a 10 (total confiança), sobre as expectativas dos indivíduos quanto ao comportamento das pessoas em geral.

Custos da participação - Mensurado a partir da percepção individual do esforço e do tempo exigidos para o envolvimento com a política. É importante destacar que essa pergunta foi feita antes daquelas referentes à participação política, o que ajuda a amenizar eventuais vieses de respostas socialmente desejáveis. Respostas negativas prévias em perguntas sobre engajamento poderiam induzir uma justificativa da não participação pelos entrevistados nessa pergunta, aumentando a frequência daqueles 
que dizem concordar com a afirmação. O efeito desta variável deve aparecer como negativo, já que o custo de oportunidade do ato de se engajar pode representar um desincentivo à participação.

Benefícios da participação - Índice composto de duas variáveis baseadas nas expectativas de benefícios individuais e coletivos originados da participação política, com intervalo de 1 (concorda fortemente) e 5 (discorda fortemente). As perguntas se referem ao quanto o entrevistado concorda com a afirmação de que a participação política é um bom meio para obter-se benefícios para si e para grupos com os quais as pessoas se importam.

\section{O Modelo de Base}

Para testar o efeito condicional da confiança interpessoal sobre o engajamento cívico é necessário, antes, esclarecer como a interação teoricamente esperada irá operar no modelo empírico. O propósito de um modelo interativo é especificar as condições sob as quais uma relação causal entre uma variável independente X e uma variável dependente $Y$ é enfraquecida ou fortalecida (AIKEN \& WEST, 1991, p.2).

Frequentemente, o estabelecimento de uma relação de causalidade implica um conjunto de condições para que uma causa teoricamente definida possa surtir seu efeito sobre um dado fenômeno (BRAMBOR et al, 2005, p.2). No caso do presente artigo, o efeito da confiança interpessoal sobre o engajamento cívico é entendido como condicionado por duas variáveis: as expectativas de benefícios e percepções de custos da participação. Dessa forma, espera-se que a confiança interpessoal atue indiretamente em conjunto com essas variáveis na propensão individual ao engajamento.

Dado que um efeito interativo representa uma hipótese condicional, isto é, uma hipótese na qual o efeito de uma variável independente $X$ sobre uma variável dependente $Y$ é condicionado por outra variável independente $Z$, não é correto interpretá-lo como o efeito médio da mudança de $X$ sobre a variável dependente, como ocorre nos modelos de mínimos quadrados mais comuns.

Em outras palavras, assim como nos modelos não-lineares, os coeficientes dos parâmetros de interação estimados nas tabelas de regressão não correspondem aos efeitos médios das variáveis independentes sobre a variável dependente. Esse ponto foi abordado por KAM \& FRANZESE (2005):

\footnotetext{
"[...] the researcher who equates a coefficient in an interactive model to an effect is treading on hazardous ground. At best the researcher will be telling a story about an effect that applies to only one of several possible conditions (e.g., when $z=0$ ). At worst, the researcher will be telling a story about an effect that applies in no logically possible condition - an effect that is logically meaningless" (KAM e FRANZESE, 2005, p.21).
}

Além disso, é errônea a afirmação de que um coeficiente significante e positivo em $X$ (ou $Z$ ) implica um efeito positivo de X (ou Z) sobre Y (BRAMBOR et al, 2005, p.10). A mesma lógica é inválida, evidentemente, para efeitos negativos. A maioria das tabelas em trabalhos sobre efeitos condicionais apresenta somente os parâmetros do modelo especificado. Embora esse seja o procedimento padrão para modelos aditivos, a mesma prática não pode ser aplicada aos modelos interativos.

Isso porque os parâmetros apresentados nas tabelas indicam somente o efeito de $X$ sobre $Y$ quando a variável condicional, $Z$, é zero, o que é frequentemente insustentável dos pontos de vista teórico e empírico (BRAmBor et al, 2005; KAm \& FRANZESE, 2005; BraUmOELLER, 2004). Assim, o efeito 
FREIRE, A. Engajamento cívico e capital social: um modelo interativo para o efeito...

condicional de uma determinada variável independente não pode ser definido a partir do nível de significância ou da magnitude do coeficiente de um termo interativo.

Tendo em vista a especificidade dos modelos interativos, o teste de uma hipótese condicional como a levantada neste artigo requer o uso de gráficos que indiquem o efeito marginal de uma variável $X$ para determinados valores de outras variáveis condicionantes.

Somente através de figuras é possível visualizar a amplitude completa do efeito condicional de uma variável. Para determinados valores de $Z$, o efeito marginal de uma variável independente $X$ sobre uma variável dependente $Y$ pode mostrar-se estatisticamente significante, enquanto para outros valores esse mesmo efeito pode ser insignificante (KAM e FRANZESE, 2005, p.33). Esse efeito somente se torna claro por meio de representações gráficas, recurso pouco presente em artigos que se utilizam de modelos interativos. A representação gráfica de efeitos condicionais é especialmente necessária nos casos em que as variáveis envolvidas no modelo interativo são contínuas.

Nesse sentido, o modelo aplicado neste artigo pode ser descrito da seguinte forma, onde apenas as variáveis de interesse estão expostas:

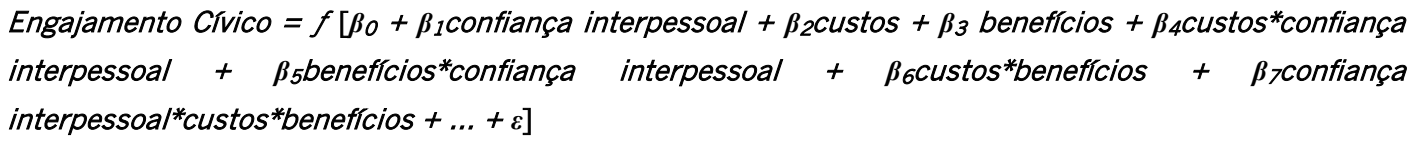

A seguir, apresento os resultados do modelo aplicado às três variáveis dependentes escolhidas.

\section{Resultados do modelo empírico e implicações teóricas}

\section{Participação em Partidos Políticos}

A primeira forma de engajamento analisada refere-se à participação em campanhas partidárias. Os partidos políticos são entidades de interesses específicos que estão invariavelmente inseridas em conflitos e disputas (RENNÓ, 2003), o que realça a importância das expectativas de benefícios. Além disso, o engajamento em partidos políticos constitui uma forma de participação que exige maior disponibilidade de tempo.

Participar de uma campanha partidária implica contribuir para atividades tais como a distribuição de panfletos, confecção de cartazes e bandeiras, levantamento de recursos, acompanhamento de eleições internas, presença em discursos, dentre outras que podem se estender ao longo de todo um ano eleitoral. Dessa forma, é razoável esperar que o efeito da confiança interpessoal para o engajamento partidário seja moderado pelas expectativas de benefícios e percepções de custos da participação.

A Figura 1 exibe o efeito marginal da confiança interpessoal $(X)$, resultante da interação com diferentes valores das variáveis sobre percepção dos custos (Z) e dos benefícios (W) da participação, sobre a variável dependente de propensão para trabalhar para um partido (Y): 
Figura 1

Efeito condicional da confiança interpessoal sobre a disposição para o engajamento partidário

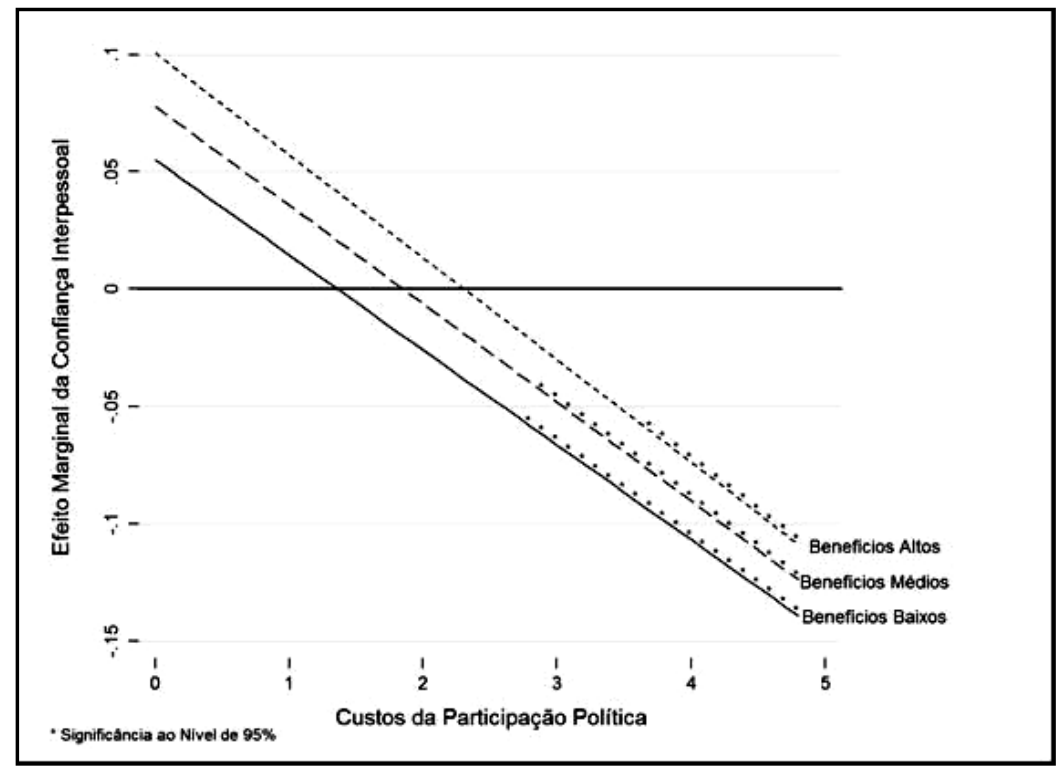

A confiança interpessoal é interagida para todos os valores da percepção de custos, mas apenas para alguns valores de interesse das expectativas de benefícios ( $\mu-\sigma$, "Benefícios Baixos"; $\mu$, "Benefícios Médios"; $\mu+\sigma$, "Benefícios Altos", sendo $\mu$ a média da variável e $\sigma$ o seu desvio-padrão). A opção por esses valores da variável de benefícios é justificada pelo fato de que grande parte da amostra se encontra entre esses valores, o que evita a inclusão de dados discrepantes na visualização do gráfico.

Minha expectativa teórica é que a confiança só deverá apresentar um efeito marginal positivo e significante em cenários onde valores mais baixos da percepção de custos $(Z<3)$ são acompanhados por valores mais altos da percepção de benefícios $(w=\mu+\sigma)$. Em outras palavras, para que a confiança interpessoal aumente a propensão individual ao engajamento cívico é necessário que a percepção de benefícios seja suficientemente alta e a percepção de custos seja suficientemente baixa. Fora desse cenário, espero que o efeito da confiança seja nulo.

A partir da Figura 1 é possível perceber como o efeito da confiança interpessoal sobre a propensão para o engajamento partidário é decrescente quanto maior for a percepção que o indivíduo tem dos custos da participação. Os asteriscos nas linhas indicam o intervalo em que o efeito marginal da confiança é estatisticamente significante sobre a variável dependente.

Quanto mais um indivíduo entende que o esforço e o tempo necessários para trabalhar para um partido político são relativamente altos, mais a confiança interpessoal reduz a propensão individual ao engajamento em uma sigla partidária, mesmo entre aqueles com expectativas altas de benefícios da participação.

O efeito marginal da confiança interpessoal passa a assumir valores negativos e estatisticamente significantes à medida que a percepção de custos se aproxima de 3, independentemente do valor das expectativas de benefícios. Esse resultado contraria as expectativas 
FREIRE, A. Engajamento cívico e capital social: um modelo interativo para o efeito...

teóricas previamente estabelecidas, as quais previam que o efeito da confiança seria nulo para valores mais altos da percepção de custos da participação.

Os achados deste artigo convergem com aqueles encontrados por Rennó $(2001,2003)$, para o contexto latino-americano, e Pattie et al (2003), para o contexto britânico, o mesmo aqui analisado, os quais identificaram uma relação negativa entre a confiança interpessoal e o engajamento em organizações político-partidárias.

Esse efeito vai na contramão da teoria do capital social, a qual prevê que a confiança atua como um estímulo positivo da cooperação entre membros da sociedade civil. De acordo com os resultados, pessoas mais confiantes e com expectativas mais positivas quanto ao comportamento alheio se distanciam de uma participação mais ativa em questões de interesse público pela via partidária. Não obstante, o efeito negativo da confiança só é significante quando as percepções de custos da participação são mais altas.

Como destacou Rennó (2003), a relação inversa entre a confiança interpessoal e o engajamento em partidos políticos levanta a hipótese de que a mobilização política é motivada pela desconfiança entre as pessoas (RENNó, 2003, p. 78). É possível que indivíduos simpáticos a partidos com determinadas ideologias desconfiem daqueles que defendem ideais diferentes dos seus, o que pode levá. los a se engajarem em uma legenda partidária específica. De fato, é esperado que a lógica da disputa político-partidária, caracterizada por antagonismos e pela disputa por recursos, seja fundamentada na desconfiança entre grupos de interesse.

É importante lembrar que a Figura 1 captura efeitos condicionais negativos e estatisticamente significantes da confiança interpessoal sobre a variável dependente que não são demonstrados por uma tabela de regressão convencional. Ao contrário do recurso às tabelas, a utilização de gráficos permite que o observador visualize não apenas se a interação ocorre entre as variáveis de seu modelo, mas também de que forma essa interação acontece.

\section{Participação em Protestos}

A participação em protestos difere consideravelmente daquela referente às siglas partidárias por constituir um tipo de ação coletiva de natureza esporádica e menos estruturada (RENNó, 2003). Dessa forma, muitos daqueles que se engajam em protestos podem fazê-lo de forma ocasional, sem aderir a organizações específicas.

Ainda assim, protestar é uma atividade que acarreta custos consideráveis, tais como a possibilidade de confrontos com a polícia. Por outro lado, as expectativas de benefícios também são relevantes, dado que, frequentemente, os protestantes buscam influenciar os processos de tomada de decisão na política. Nesse sentido, é possível que as dimensões instrumentais do protesto condicionem o efeito da confiança interpessoal na decisão de um indivíduo em participar ou não desse tipo de ação coletiva.

A Figura 2, ao contrário dos resultados da Figura 1, revela um efeito marginal positivo e estatisticamente significante da confiança interpessoal quando as expectativas de benefícios e de custos da participação são relativamente altas. A confiança interpessoal mostrou um efeito marginal positivo e estatisticamente significante sobre a propensão para o engajamento em protestos dentre aqueles que apresentaram expectativas altas $(\mu+\sigma)$ de benefícios derivados da participação política. 
No entanto, esse mesmo efeito mostrou-se diretamente proporcional às expectativas de custos da participação. Quanto maiores os custos, maior o efeito marginal da confiança sobre a propensão ao engajamento em protestos. Sem embargo, o efeito marginal positivo da confiança interpessoal perde significância dentre aqueles com expectativas altas de benefícios quando a percepção de custos, Z, se aproxima de seu valor máximo. 0 efeito marginal da confiança para as expectativas médias e baixas de benefícios foi decrescente, embora positivo e insignificante (exceto para um pequeno intervalo das expectativas médias de benefícios), quanto maiores as percepções de custos.

Figura 2

Efeito condicional da confiança interpessoal sobre a disposição para o engajamento em protestos

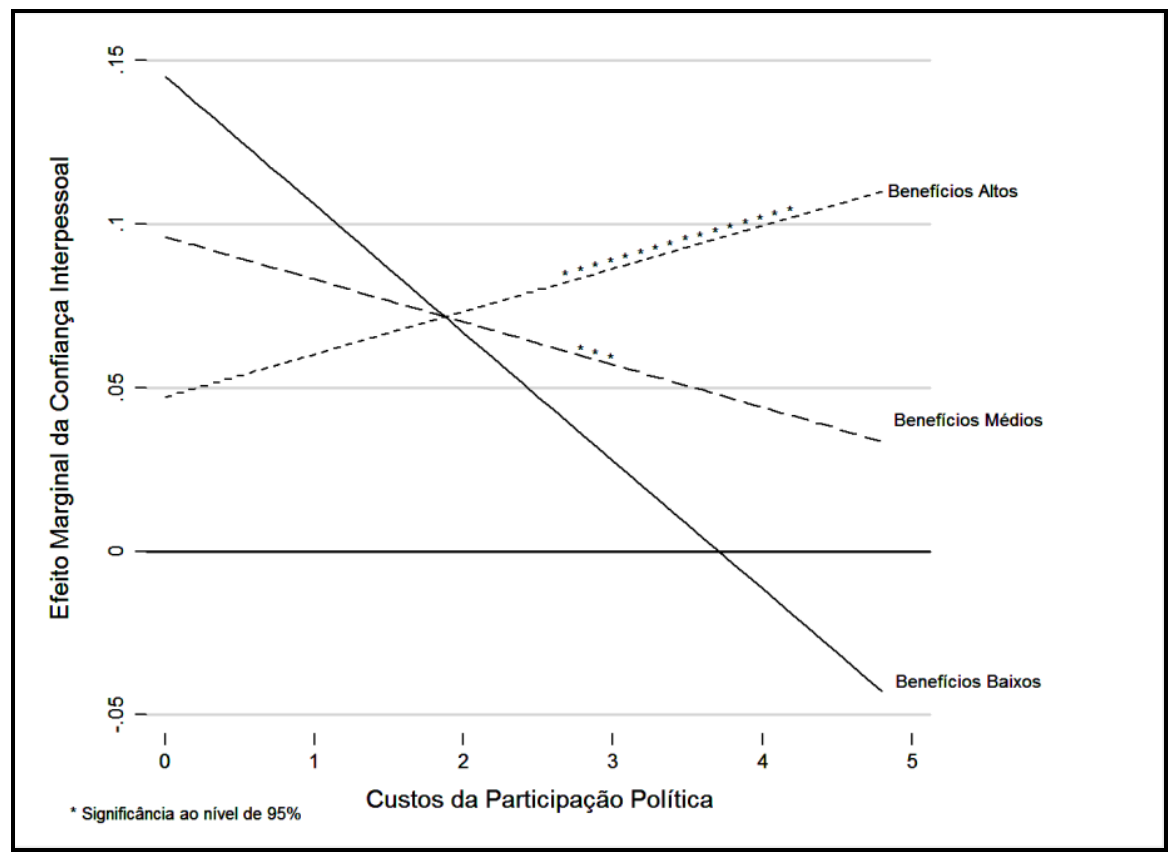

É possível que a natureza dos protestos implique maiores riscos para os envolvidos (i.e., confrontos com a polícia ou com grupos de protestantes rivais), o que aumentaria a importância da confiança social como garantidora da coesão de grupo, fomentando expectativas positivas acerca da conduta alheia e reduzindo a sensação de risco associada a esse tipo de ação coletiva. Cabe salientar aqui a distinção entre as formas convencionais e não convencionais de participação política, notada por Borba \& Ribeiro (2010) e Borba (2012). Como observam os autores, os custos associados às diferentes formas participação podem explicar os diferentes efeitos que determinadas variáveis exercem sobre o grau de envolvimento dos cidadãos em ações coletivas. $O$ ato de protestar constitui um tipo de engajamento pouco convencional precisamente em virtude de seus custos, em contraste ao engajamento partidário, o qual, apesar de sua natureza conflituosa (BORBA, 2012; VERBA, NIE e KIM, 1971) não envolve riscos aos participantes. Essa distinção pode ser um fator explicativo para os diferentes efeitos da confiança interpessoal nessas formas de participação. 
FREIRE, A. Engajamento cívico e capital social: um modelo interativo para o efeito...

Ademais, vale mencionar que as obras de Putnam (2006 [1993]) e outros teóricos do capital social associavam a confiança interpessoal a comportamentos aquiescentes com as leis (RENNÓ, 2001). No entanto, os achados apresentados neste artigo indicam que ela pode servir, também, à contestação pública dessas mesmas leis.

Chama atenção a relação positiva da percepção de custos da participação com o efeito marginal da confiança, quando há expectativas altas de benefícios. O tempo e o esforço dispensados à participação parecem contribuir para um efeito positivo da confiança sobre a propensão para o engajamento em protestos. Quanto maiores as percepções de benefícios e de custos do engajamento, maior o efeito marginal da confiança sobre a propensão para participar de um protesto.

Essa relação direta com os custos significa que a confiança só representa um diferencial para a propensão ao engajamento quando um indivíduo passa a entender que a participação política exige muito de seu tempo e de seus esforços. Aqueles que percebem os benefícios do engajamento em protestos como altos e seus custos como baixos são pouco afetados pela confiança, ou seja, sua participação nesse tipo de atividade não parece depender de suas expectativas quanto à conduta de outras pessoas. Essa conclusão se aproxima da perspectiva teórica de Gambetta (2000), a qual prevê que ações baseadas na cooperação podem ser iniciadas independentemente da confiança, dependendo dos interesses em questão.

Em suma, a confiança parece ter um efeito compensatório em relação aos custos do engajamento em protestos. Diante de expectativas altas de benefícios do protesto, quanto mais um indivíduo é desmotivado a participar de tal atividade, em virtude de seus custos, mais a confiança representa um incentivo positivo compensatório ao engajamento nesse tipo de ação coletiva.

Por fim, é necessário destacar a irrelevância da confiança interpessoal quando as expectativas de benefícios da participação são médias ou baixas. Quando não há percepções altas de benefícios sobre o engajamento em protestos, a confiança interpessoal ainda exerce efeitos positivos, porém estatisticamente insignificantes e decrescentes (novamente, exceto para um pequeno intervalo das expectativas médias de benefícios), quanto maior a percepção de custos. Nesse sentido, a natureza instrumental da ação coletiva aparece como um importante fator que condiciona o efeito da confiança sobre a disposição individual para a participação em protestos.

\section{Participação em associações voluntárias}

A terceira variável dependente de propensão para o engajamento refere-se às associações voluntárias. Essas associações seriam, segundo Tocqueville (2004 [1835]), "escolas da democracia". Nelas, os cidadãos aprenderiam os valores do associativismo e da cooperação, essenciais para a manutenção de um regime democrático. Diversos teóricos do capital social enfatizaram a importância da confiança interpessoal para a formação de associações autônomas da sociedade civil (PUTNAM, 2006 [1993]; FUKUYAMA, 2001; INGLEHART, 1988).

A ilustra um interessante resultado sobre o efeito marginal da confiança interpessoal para a propensão ao engajamento em associações. A relação entre o efeito da confiança e os custos da participação é direta, embora nem sempre positiva, para quaisquer níveis de expectativas de custos ou benefícios originados da participação política, ainda que essa relação só atinja significância a partir do momento em que os custos da participação começam a se aproximar de 3. 
Figura 3

Efeito condicional da confiança interpessoal sobre a disposição para o engajamento em associações voluntárias

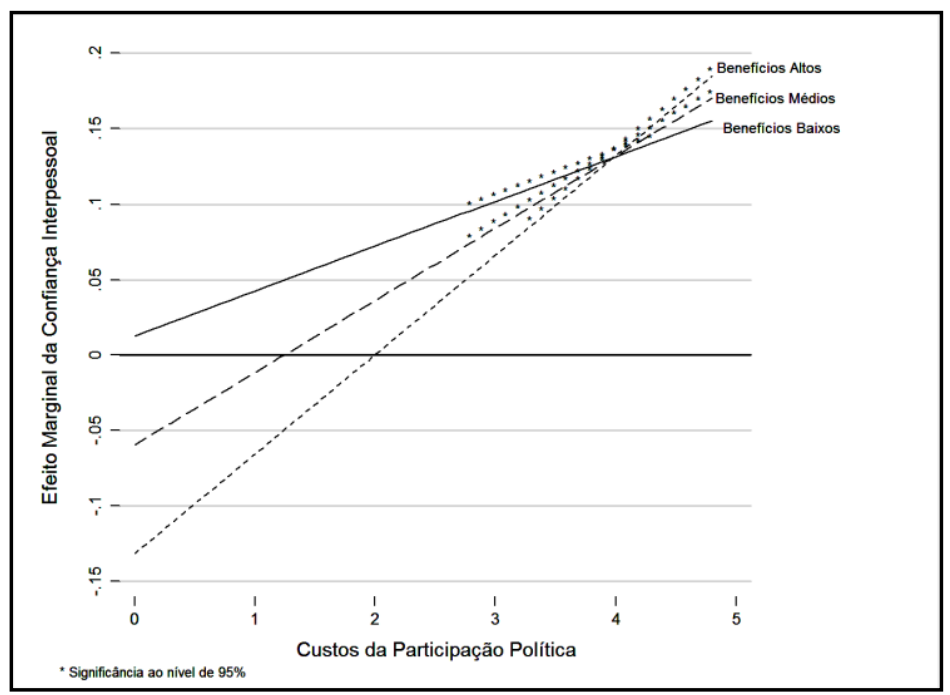

Isto é, quanto mais um indivíduo entende que sua participação em assuntos de interesse público requer muito de seu tempo e de seu esforço, mais a confiança interpessoal representa um diferencial positivo na propensão individual para o engajamento em associações. Resumindo, a confiança aparece como facilitadora da cooperação quanto mais a participação em associações voluntárias tende a ser vista como uma atividade dispendiosa.

É possível perceber que os efeitos marginais da confiança são virtualmente idênticos a partir do momento em que os custos são maiores ou iguais a 4 , independentemente das expectativas de benefícios. Isso ocorre, provavelmente, em virtude do pequeno número de observações em que a percepção de custos é máxima, o que acaba alargando o intervalo de confiança.

Dentre as variáveis dependentes contempladas, o efeito marginal positivo da confiança interpessoal apresentou sua maior relevância na propensão ao associativismo. A confiança mostrou-se como um estímulo positivo à disposição individual para ingressar em associações, quando aliada a aspectos motivacionais. Esse resultado diverge daqueles encontrados nas pesquisas de Rennó (2001, 2003), ainda que para outro contexto, e Pattie et al (2003), onde a confiança foi constatada como negativamente relacionada ao associativismo.

A confiança aparece, no caso das associações voluntárias, como um facilitador da cooperação, como prevê a teoria do capital social. Entretanto, é necessário que as percepções de custos e de benefícios atinjam determinados pontos para que o efeito da confiança seja positivo e relevante para a propensão ao engajamento nessas associações. Quando a percepção de custos do engajamento é baixa, a confiança tem efeitos insignificantes e até mesmo negativos, independentemente das expectativas de benefícios.

É possível que indivíduos mais confiantes sejam mais dispostos a se comunicarem com pessoas que fazem parte de seus círculos sociais, dando margem à formação de associações voluntárias capazes 
FREIRE, A. Engajamento cívico e capital social: um modelo interativo para o efeito...

de canalizar interesses específicos. Suas expectativas positivas quanto ao comportamento alheio podem facilitar a interação social necessária para a formação dessas associações, compensando eventuais custos vinculados ao associativismo.

Ao contrário dos partidos políticos, as associações voluntárias não necessariamente visam influenciar os processos de tomada de decisão na política. Nesse sentido, frequentemente, o associativismo está vinculado a interações "endógenas" entre seus membros. Isto é, aqueles que compõem associações voluntárias podem não estar interessados no conflito característico da interação político-partidária, mas em reforçar vínculos de cooperação com pessoas que fazem parte de suas comunidades ou grupos de interesse.

De acordo com Rennó (2003), há uma notável diferença entre associações de âmbito nacional, com objetivos políticos voltados para a disputa da alocação de recursos, e as associações locais, voltadas à resolução de problemas cotidianos (RENNÓ, 2003, p.72). A confiança interpessoal, de acordo com os resultados apresentados neste artigo, tem o efeito de incentivar a formação de grupos de cidadãos com interesses em comum, preocupados com o provimento de bens coletivos em seus círculos sociais. Esse efeito, por sua vez, é condicionado pelas expectativas individuais de custos e de benefícios da ação coletiva.

Embora os objetivos primários dessas associações não sejam necessariamente políticos, é interessante observar que a confiança tem maiores efeitos quanto maior for a expectativa de benefícios da participação na política e em questões de interesse público. Quanto mais um indivíduo entende que sua participação é capaz de trazer benefícios para si e para outras pessoas, maior é o efeito positivo da confiança sobre a propensão para o engajamento em tais associações.

Não obstante, ainda que a relação entre a confiança e os custos da participação seja contrária àquela prevista pela hipótese levantada, há uma relação condicional entre os interesses próprios dos indivíduos e suas impressões sobre o comportamento de outras pessoas. As razões instrumentais da participação reforçam o efeito positivo da confiança para o engajamento em associações voluntárias.

A seguir, apresento as conclusões deste artigo, abordando os horizontes teórico e metodológico sobre o estudo do engajamento cívico e do capital social.

\section{Conclusões}

Este artigo buscou investigar o papel da confiança interpessoal para o fomento a formas de participação política diferentes da participação eleitoral. Apesar da centralidade desse conceito para a teoria do capital social, os resultados aqui expostos indicam que o efeito da confiança interpessoal sobre o engajamento cívico é condicional. Isto é, a confiança afeta diferentes indivíduos de maneira distinta.

As expectativas de benefícios e percepções de custos da participação moderam o efeito da confiança sobre a disposição individual para o engajamento cívico. No caso do engajamento partidário, a confiança teve um papel inverso àquele preconizado pela teoria do capital social, ainda que condicionado por expectativas de benefícios e percepções de custos.

Entretanto, a confiança interpessoal só exerceu efeitos negativos sobre o engajamento partidário quando a percepção de custos da participação política assumiu valores um pouco mais altos. Isto é, pessoas que já são pouco motivadas a se engajarem em partidos são ainda menos motivadas pela confiança em outras pessoas. 
OPINIÃO PÚBLICA, Campinas, vol. 20, no 2, agosto, 2014, p. 273-290

Esse padrão de condicionamento foi inverso àquele constatado para o engajamento em protestos e em associações voluntárias. Nesses casos, a percepção de custos da participação condicionou positivamente o efeito da confiança sobre a propensão ao protesto e ao associativismo. Quanto maiores os custos, maiores os efeitos marginais da confiança interpessoal. Especificamente, o efeito da confiança só se mostrou positivo para os protestos quando expectativas altas de benefícios foram associadas a percepções altas de custos da participação.

O efeito condicional diferenciado da confiança para diferentes de formas de engajamento suscita a interessante hipótese levantada por Pattie et al (2003) de que a confiança é "uma faca de dois gumes". Como destacam os autores, pessoas muito confiantes podem se tornar ativas por acreditarem que suas ações surtirão efeito sobre o sistema político, já que podem contar com a ajuda de outros. Da mesma forma, aqueles que muito confiam em outras pessoas podem acreditar que seus interesses estão bem resguardados por pessoas idôneas tanto na política quanto em suas comunidades locais, o que pode servir como um incentivo à inação.

Inversamente, a desconfiança pode fomentar a ação de ativistas que temem que a ação de grupos com interesses antagônicos aos seus possam prejudicá-los. Por outro lado, a proliferação da desconfiança entre as pessoas poderia dar margem ao cinismo político e à total descrença na capacidade de mudança do status quo através da participação política.

De todo modo, o mais importante sobre os resultados aqui expostos é que a confiança interpessoal necessita estar atrelada a determinados aspectos motivacionais da participação para que surta algum efeito positivo, ainda que modesto, sobre a propensão ao engajamento cívico. Não faz sentido, portanto, esperar que a simples impressão positiva sobre a conduta de outrem sirva como o principal motor da participação em organizações e movimentos coletivos da sociedade civil. Ademais, é importante destacar que o efeito condicional da confiança interpessoal constatado pelo modelo é relativamente fraco quando comparado ao de variáveis como conhecimento político e educação formal (FREIRE, 2012).

A opção metodológica adotada neste artigo procurou explicitar o vínculo causal entre a confiança, as motivações e a participação cívica. As hipóteses e modelos condicionais podem contribuir para avanços no teste de teorias sobre fenômenos complexos que envolvem múltiplos fatores. A maioria dos fenômenos de interesse da Ciência Política e das demais Ciências Sociais é de natureza multifacetada, o que dificulta o estabelecimento de relações causais simples e incondicionais.

Desse modo, não faz sentido pensar que a confiança interpessoal seja capaz de afetar as pessoas da mesma forma. Independentemente de como a confiança seja entendida, seja como uma forma de comportamento manifestada em nível individual, seja como uma instituição informal característica de determinados contextos sociais, sua capacidade de facilitar a cooperação é limitada e diferenciada.

Em suma, como Coleman (1988) havia destacado em sua teorização sobre o capital social, é necessário entender as motivações que impulsionam as pessoas a formarem grupos com interesses em comum. Este artigo representa um primeiro esforço nesse sentido, de forma que pesquisas futuras poderão explorar o entrelaçamento entre a confiança e as motivações para o engajamento mais a fundo. 
FREIRE, A. Engajamento cívico e capital social: um modelo interativo para o efeito...

\section{Referências Bibliográficas}

AIKEN, L.; WEST, S. Multiple Regression: Testing and Interpreting Interactions. London: Sage Publications, 1991.

AldRICH, J.; H. "Rational Choice and Turnout". American Journal of Political Science, vol. 37, n¹, p. 246-278, Febr.1993.

Almond, G.; Verba, S. The Civic Culture: Political Attitudes and Democracy in Five Nations. Newbury Park: Sage Publications, 1989 [1963].

Ansolabehere, S.; Rodden, J.; S.; James M. "The Strength of Issues: Using Multiple Measures to Gauge Preference Stability, Ideological Constraint, and Issue Voting". The American Political Science Review, vol. 102, n², p. 215.232, May 2008.

BAUmoL, W. J. "It Takes Two to Tango, or Sind 'Separable Externalities' Überhaupt Möglich?” Journal of Political Economy, 84, p.381-387, June 1976.

BORBA, J. "Participação política: uma revisão dos modelos de classificação." Revista Sociedade e Estado, vol. $27, \mathrm{n}^{\circ} 2$, mai./ago. 2012.

; RIBEIRO, E. A. "Participação convencional e não convencional na América Latina." Revista Latinoamericana de Opinión Pública, nº, Artículos, 2010.

Brady, H. E.; Verba, S.; Schlozman, K. L. "Beyond Ses: A Resource Model of Political Participation." The American Political Science Review, vol. 89, p. 271-294, June 1995.

Brambor, T.; ClaRk, W. R.; Golder, M. "Understanding Interaction Models: Improving Empirical Analyses." Political Analysis, 14, p. 63.82, May 2005.

Braumoeller, B. F. "Hypothesis Testing and Multiplicative Interaction Terms." International Organization, 58, p 807.820, Oct. 2004.

BREHM, J.; RAHN, W. "Individual level evidence for the causes and consequences of social capital". American Journal of Political Science, vol.41, n³, 1997

Coleman, J. S. "Social Capital in the Creation of Human Capital." American Journal of Sociology, Supplement: Organizations and Institutions: Sociological and Economic Approaches of Social Structure, vol. 94, p. 95-120, 1988.

Claibourne, M. P.; Martin, P. S. "Trusting and Joining? An Empirical Test of the Reciprocal Nature of Social Capital." Political Behavior, vol. 22, nº 4, p. 267.291, 2000.

Downs, A. An Economic Theory of Democracy. New York: Happer \& Row Publishers, 1957.

ELSTER, J. Ulysses and the Sirens: Studies in Rationality and Irrationality. Cambridge: Cambridge University Press, 1979.

FIORINA, M. P. Extreme voices: a dark side of civic engagement. In: SkocPol, T. \& FIORINA, M.P. Civic Engagement in American Democracy. Washington: Brookings Institution Press, 1999.

Parties, Participation, and Representation in America: Old Theories Face New Realities. American Political Science Association, 2001. Disponível em:

<http://www.stanford.edu/ mfiorina/Fiorina\%20Web\%20Files/Fiorina\%20SOD.pdf>. Acesso em: 10 maio 2014.

FREIRE, A. O. G. "Engajamento Cívico e Capital Social: Um Estudo Empírico sobre o Papel da Confiança Interpessoal para a Resolução dos Dilemas da Ação Coletiva." Dissertação de Mestrado, Universidade de Brasília, 2012.

Fukuyama, F. "Social Capital, Civil Society and Development." Third World Quarterly, vol. 22, p. 7.20, Febr. 2001.

GambettA, D. Can We Trust Trust? In: GambetTA, D. (org.). Trust: Making and Breaking Cooperative Relations. Department of Sociology, University of Oxford, 2000.

INGLehart, R. "The Renaissance of Political Culture." The American Political Science Review, vol. 82, Issue 4, p. 1203. 1230, Dec. 1988.

Jackman, R. W.; Miller, R. A. "Social Capital and Politics." Annual Review of Political Science, p. 47-73, 1998.

Johnson, J. "Conceptual Problems as Obstacles to Progress in Political Science: Four Decades of Political Culture Research." Journal of Theoretical Politics, Sage Publications, London, p. 87-115, Jan. 2003. 


\section{OPINIÃO PÚBLICA, Campinas, vol. 20, no 2, agosto, 2014, p. $273-290$}

KAM, C.; FRAnZESE, R. Modeling and Interpreting Interactive Hypotheses in Regression Analysis: A Brief Refresher and Some Practical Advice. Unpublished Manuscript, University of Michigan, 2005. Disponível em <http://www. personal.umich.edu/ franzese/FranzeseKam.Interactions.pdf>. Acesso em: 10 maio 2014.

LIPSET, S. M. Political Man: the social basis of politics. New York: Double Day, 1960.

LeVI, M. "Social and unsocial capital: Review of Robert Putnam’s Making Democracy Work." Politics and Society, n²4, p.45-55, March 1996.

NuRmi, H. Rationality and Public Goods: Essays in Analytical Political Theory. Commentations Scientiarium Sociolium, 9 , 1977.

OLson, M. The Logic of Collective Action: Public Goods and the Theory of Groups. Cambridge: Harvard University Press, 1965.

Ostrom, E. "Collective Action and the Evolution of Social Norms." Journal of Economic Perspectives, vol. 14, $\mathrm{n}^{\circ} 3$, p.137-158, 2000.

Pattie, C.; Seyd, P.; Whiteley, P. "Citizenship and Civic Engagement: Attitudes and Behaviour in Britain." Political Studies, vol. 53, p. 443.468, 2003.

Putnam, R. Comunidade e Democracia: a experiência da Itália Moderna. São Paulo: FGV Editora, 2006 [1993].

RENNÓ, L. R. "Confiança interpessoal e comportamento político: microfundamentos da teoria do capital social na América Latina." Opinião Pública, vol. VII, n¹, p.33-59, 2001.

"Estruturas de Oportunidade e Engajamento em Organizações da Sociedade Civil: Um Estudo Comparado Sobre a América Latina." Revista de Sociologia Política, n² 21, p.71.82, nov. 2003.

Riker, W. H.; ORdeShook, P. C." A Theory of the Calculus of Voting." The American Political Science Review, vol. 62, $\mathrm{n}^{\circ} 1$, p. 25-42, March 1968.

Runge, C. F. "Institutions and the Free Rider: The Assurance Problem in Collective Action." The Journal of Politics, vol. 46, nº 1, p.154-181, Febr. 1984

Seligson, M.; Renno, L. R. "Mensurando Confiança Interpessoal: Notas acerca de um Conceito Multidimensional." Dados, $\mathrm{n}^{\circ} 4$, p. $783 \cdot 803,2000$

TocqueVILle, A. A Democracia na América. São Paulo: Martins Fontes, 2004 [1835].

VerBA, S.; NIE, N. H.; KIM, J.O. The modes of democratic participation: a cross-national comparison. Beverly Hills, California: Sage Publications, 1971.

Verba, S.; Brady, H.E.; Schlozman, K.L. "Action and political activity”. Journal of Theorical Politics, vol.12, n³, 2000.

Alessandro Freire - alessandro.freire@gmail.com

Submetido à publicação em maio de 2013.

Versão final aprovada em abril de 2014 